\section{HSE}

Historia Social y de la Educación

Social and Education History
Hipatia Press

www.hipatiapress.com

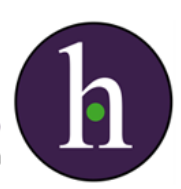

Instructions for authors, subscriptions and further details:

$\underline{\text { http://hse.hipatiapress.com }}$

\title{
La mujer que salvaba a los niños.
}

Elena Duque Sánchez ${ }^{1}$

1) Universitat de Barcelona (España)

Date of publication: February $23^{\text {rd }}, 2020$

Edition period: Edition period: February 2020-June 2020

To cite this article: Duque, E. (2020). La mujer que salvaba a los niños. [Review of the book]. Social and Education History 9(1), 121-123. doi:10.17583/hse.2020.5145

To link this article: http://dx.doi.org/10.17583/hse.2020.5145

\section{PLEASE SCROLL DOWN FOR ARTICLE}

The terms and conditions of use are related to the Open Journal System and to Creative Commons Attribution License (CC-BY). 


\section{Reviews (I)}

Mulley, C. (2018). La mujer que salvaba a los niños. Barcelona: Alienta Editorial.

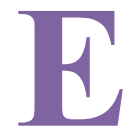

1 presente libro es una biografía de Eglantyne Jebb, nacida en 1876 en Ellesmere (Reino Unido) en una familia de clase media intelectual, que tal y como se detalla en el libro, poseían una casa en la que en todas las habitaciones era posible encontrar libros. Una pasión, la lectura que Eglantyne inició desde pequeña y no abandonó hasta su muerte. Licenciada en historia por la universidad de Oxford decidió en 1899 comenzar a dar clases en una escuela para niños y niñas de clase trabajadora y con situación económica precaria. Esta experiencia la llevó a apasionarse por la educación y por la búsqueda de mejores metodologías de aprendizaje y a estudiar la carrera de magisterio.

Tal y como se muestra a través del libro, los varios problemas de salud que tuvo nuestra Eglentyne generaron que tuviera que pasar largos períodos sin trabajar. Fue a partir de 1916 que empezó a unirse aún más a su hermana Dorothy, que movida afiliada a Liga internacional por la paz y la libertad y activista pacifista. Dorothy estaba convencida que la promoción de una visión más humanitaria de los enemigos de la Gran Bretaña se podría conseguir una paz negociada (recordemos que para esas fechas, ya se había iniciado la I Guerra Mundial). Uno de los proyectos de Dorothy para combatir la información sesgada sobre la guerra en los periódicos de Gran Bretaña, fue la de publicar noticias de la misma guerra, pero en periódicos de los países enemigos o neutrales. Con el objetivo de mostrar el sufrimiento de ambos bandos y no justificar la guerra. Entre su equipo de colaboradoras y traductoras se encontraba su hermana Eglentyne que dominaba con fluidez el francés y el alemán. 
En 1919, entre cuatro y cinco millones de niños y niñas se estaban muriendo de hambre en Europa. Dorothy creó en marzo la Oficina de Información sobre el Hambre con el objetivo de recoger información fiable de la verdadera situación de los niños y niñas víctimas colaterales de la guerra. En estos momentos se empezaron también a elaborar y distribuir folletos de niños y niñas austríacas hambrientas, mostrando así las secuelas que estaba teniendo la guerra para un colectivo totalmente inocente. Motivo por el que fue detenida Eglentyne y otra compañera y llevadas a juicio. El motivo fue la distribución de propaganda no autorizada por el gobierno.

La propaganda involuntaria de dicho juicio fue aprovechada por las dos hermanas y convocaron una "Reunión contra la hambruna" el 19 de mayo de 1919. Fecha que se considera la creación de Save de Children. En dicha reunión Eglentyne dio un mensaje muy poderoso sobre los niños y niñas: "Tenemos un único objetivo, salvar a tantos como sea posible. Tenemos una sola regla, les ayudaremos sea cual sea su país, sea cual sea su religión" (p. 319).

Aunque existían otras organizaciones humanitarias en terreno de guerra, la realidad era que los niños y sus necesidades no eran tenidos en cuenta. Siendo así que Save the Children se convirtió en la primera organización benéfica especial creada para niños sin hogar y la primera fundada por mujeres. También es la mayor organización internacional independiente para la mejora de la infancia. Y, por lo tanto, también ha contribuido a crear conciencia de la existencia de derechos de un colectivo totalmente invisibilizado como eran los niños y niñas.

A partir de su creación, el trabajo se centró en recaudar fondos para hacer llegar la ayuda al máximo de niños y niñas y a crear una conciencia de que éstos ser considerados terreno neutral. Para hacer aún más clara esta posición de la asociación, se decidió poner su sede en Ginebra, considerado país neutral.

Al trabajo en Save the Children como presidenta de Eglentyne, se unió su empeño por crear un documento con reconocimiento que reuniera los derechos imprescindibles de los niños y niñas, tal y como se detalla en el capítulo 15, llevó a Eglantyne a elaborar un inicial redactado llamado "Carta del niño" con cinco puntos que fue el punto de partida de la promulgación de los Derechos del niño y la niña por parte de las Naciones Unidas. 


\section{HSE - Social and Education History, 9(1) 123}

En este libro se pueden encontrar los detalles de la trayectoria de una mujer que se rebeló también contra las imposiciones sociales de su época y consiguió hacer partícipe a la humanidad de la necesidad de poner en el centro del bienestar a los niños y niñas.

Elena Duque Sánchez Universidad de Barcelona elenaduquesa@ub.edu 